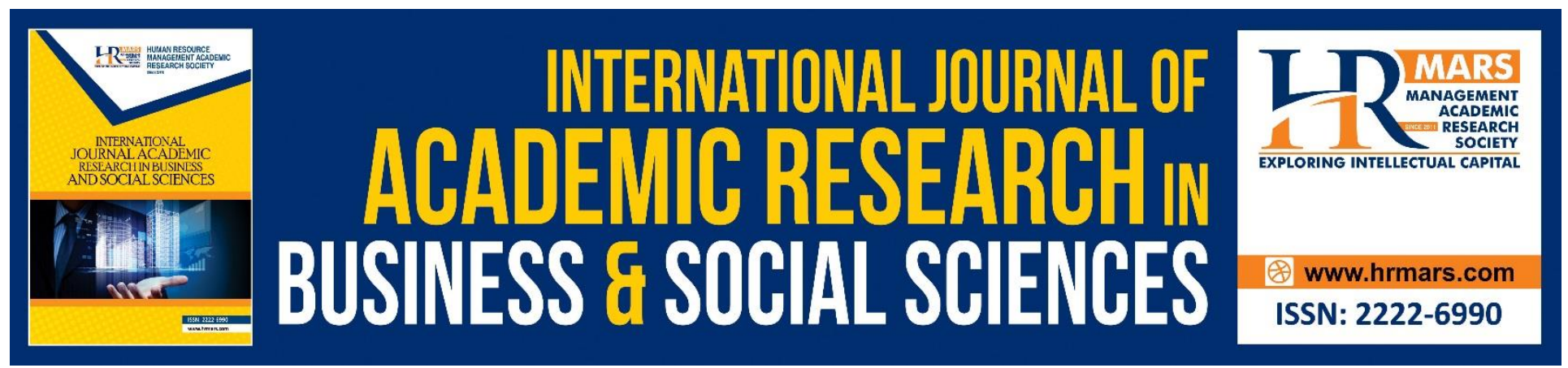

\title{
The Effect of the Private Health Insurances and Health Financing on the Population Health in the European Countries
}

\section{Alexandra Pintea, Razvan Dorel Pauna, Paul Sorin Lazar}

To Link this Article: http://dx.doi.org/10.6007/IJARBSS/v10-i10/7762

DOI:10.6007/IJARBSS/v10-i10/7762

Received: 29 July 2020, Revised: 25 August 2020, Accepted: 11 September 2020

Published Online: 09 October 2020

In-Text Citation: (Pintea, Pauna, \& Lazar, 2020)

To Cite this Article: Pintea, A., Pauna, R. D., \& Lazar, P. S. (2020). The Effect of the Private Health Insurances and Health Financing on the Population Health in the European Countries. International Journal of Academic Research in Business and Social Sciences. 10(10), 143-158.

Copyright: (c) 2020 The Author(s)

Published by Human Resource Management Academic Research Society (www.hrmars.com)

This article is published under the Creative Commons Attribution (CC BY 4.0) license. Anyone may reproduce, distribute, translate and create derivative works of this article (for both commercial and non-commercial purposes), subject to full attribution to the original publication and authors. The full terms of this license may be seen

at: http://creativecommons.org/licences/by/4.0/legalcode

Vol. 10, No. 10, 2020, Pg. 143 - 158

http://hrmars.com/index.php/pages/detail/IJARBSS

JOURNAL HOMEPAGE

Full Terms \& Conditions of access and use can be found at http://hrmars.com/index.php/pages/detail/publication-ethics 


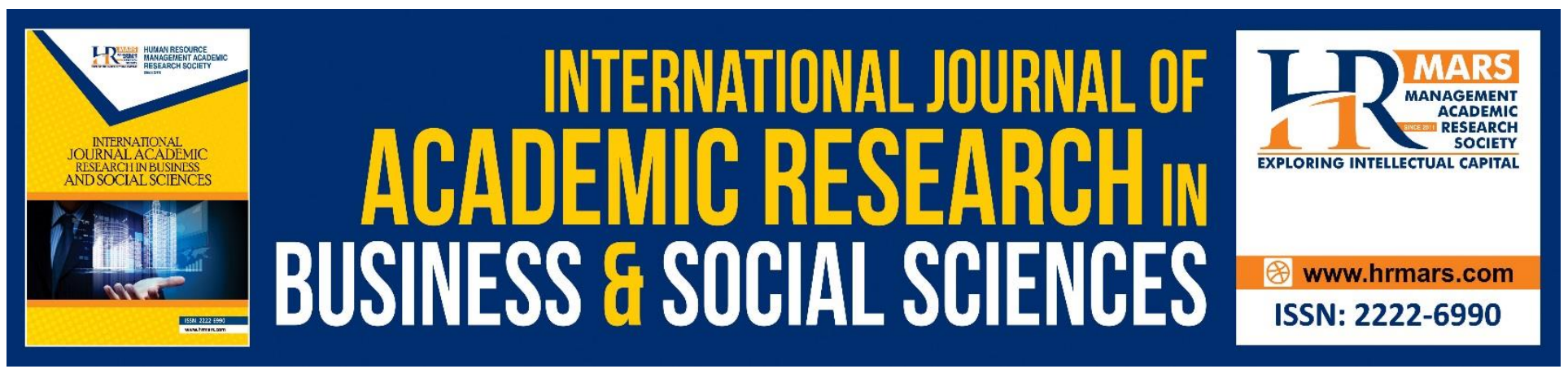

\title{
The Effect of the Private Health Insurances and Health Financing on the Population Health in the European Countries
}

\author{
Alexandra Pintea, Razvan Dorel Pauna \\ Babes-Bolyai University of Cluj Napoca, Faculty of Political, Administrative and Communication \\ Sciences, Department of Public Administration and Management \\ Email: alexandrapinteaubb@gmail.com

\section{Paul Sorin Lazar} \\ Babes-Bolyai University of Cluj Napoca, Faculty of Business, Department of Hospitality Services
}

\begin{abstract}
This empirical study addresses the role of economic and institutional determinants on population health, estimated by life expectancy and accessibility to good quality medical services. Several national health systems are described descriptively and analytically. The practical application considers 30 European countries for which data on all necessary variables are available. The data are provided by international institutions such as the World Bank, Insurance Europe, Global Health Security and national institutions from the sampled countries. The results of the OLS cross-country regressions clearly demonstrate the positive role of health financing and the decentralization of the national health system. Instead, the role of private health insurance remains debatable, as does its complementarity or substitutability in relation to public funding. Based on the main results, recommendations are formulated regarding possible adjustments for an increased efficiency of the medical system and possible future research directions, especially regarding the role of the financing structure and the type of decentralization of the medical services.
\end{abstract}

Keywords: Private Health Insurance, Health Financing, Life Expectancy, Global Health Security, European Countries

\section{Introduction and Literature Review}

In Europe, there are currently no health systems that are financed exclusively from public or private resources, the financing being made from several sources, both public and private, combining financing from the state budget, from public health insurance. and private, co-payment or direct payment for medical services by patients. Although these funding systems differ from country to country, what they have in common is the need for a comprehensive health funding mechanism, a well-trained and adequately paid workforce, reliable information on which to base decisions and 
INTERNATIONAL JOURNAL OF ACADEMIC RESEARCH IN BUSINESS AND SOCIAL SCIENCES Vol. 10, No. 10, 2020, E-ISSN: 2222-6990 @ 2020 HRMARS

policies in the country. health, as well as the logistics and technology needed to deliver quality medicines and medical services.

National health insurance systems pursue three fundamental axes. Health needs and health demand condition the current and future mission of health systems. The financing and organization of health sectors, as well as the infrastructure of health systems and their use are important to understand the nature, structure and individual characteristics of the health systems of the states of the European Union. All health systems strive to meet the health and medical needs of the population. It is important to know to what extent health demand adequately reflects the real needs of the population and to what extent the supply of health care and the use of health services are satisfactory.

There are three predominant financing systems in the countries of the European Union

1. The "Beveridge" model is characterized by public funding based on taxes.

2. The "Bismark" model, in which case the financing is made through compulsory insurance.

3. The model of private financing through voluntary insurance.

At present, the financing and organization of the health system in the EU Member States follow the national institutional, political and socio-economic traditions. These are embodied in a number of social objectives in terms of funding and the provision of efficient and affordable healthcare services. Criteria used to assess the extent and nature of healthcare needs include population characteristics, as well as health indicators such as life expectancy, morbidity and mortality. These indicators can also be considered as indicators of health systems. The relative value, distributed on each objective, varies in a considerable way, according to the national systems, as well as between the health sector and other sectors of action of the public power within each country. In order to finance a health system, it is necessary to collect money from the population in order to be able to contract medical service providers. The main objective of the systems is to distribute the costs of medical services between sick and healthy people and to modulate them according to the resources available to each individual. This solidarity mechanism reflects the consensus in the countries of the European Union that health cannot be left to market mechanisms (Pintea, 2020).

Health systems in the countries of the European Union are financed by public contributions or by direct contributions. Each Member State has developed its own funding mechanisms. All systems are more or less hybrid, insofar as they rely on a combination of funding sources, but most funds are controlled directly or indirectly by the state. Only a small proportion of services are paid for directly.

At a time when the national health service is booming, medical resources and services are provided mainly by public services and access to them is free. No health system in the EU Member States is exclusively state-owned. In most EU countries, primary health care is exempt from payment under a mixed system that combines private liberal medicine with public medicine. The importance of providing primary health care varies depending on the health system, as evidenced by the different percentages of general practitioners in the total medical staff. Some Member States are tempted to reduce the number of specialists, whose services are generally more expensive, and to strengthen the role of general medicine. The expectations of the general public in terms of infrastructure and 
INTERNATIONAL JOURNAL OF ACADEMIC RESEARCH IN BUSINESS AND SOCIAL SCIENCES Vol. 10, No. 10, 2020, E-ISSN: 2222-6990 @ 2020 HRMARS

health care are major consequences of health policy: on the one hand, these expectations are considered as a factor in assessing costs, and on the other hand, user satisfaction is an element. evaluation and implementation of reforms in health systems.

The level of user satisfaction is to a certain extent proportional to the level of health spending, except in the case of Italy, with most consumers showing a low level of satisfaction, and Danes who spend little are mostly very satisfied with their health system. Citizens of southern European countries are generally less satisfied with the medical services provided to them than citizens of other EU Member States. Today, there is some dissatisfaction in all EU member states with the ways in which medical services are financed and provided. The main common issues that occupy various places in the order of national concerns are their shortcomings in terms of equity and equality in access to health care, control of expenditure, resource efficiency and quality control of health services. These common concerns lead to convergent or specific strategies, as appropriate.

Regarding the social stability plan, the priority consists in guaranteeing medical care for the elderly, better adapted to their needs, being privileged the research of a balance between home care, community care and hospital services. On the other hand, the aging of the population translates into a progression of chronic diseases. This leads to more efforts to prevent easily preventable diseases, with or without medical care. Preventive care is a potential economic alternative to health care based on expensive technologies. While the principle of universal access to care is used in most Member States, equal access remains a constant concern of health systems, they depend on many factors that are not directly related to health. Efforts in this area are multidisciplinary and cross-sectoral, with a focus on health education as well as the fight against exclusion.

All EU Member States are implementing policies to increase spending on an aging population, the financial implications of technological development, and rising consumer expectations that appear unexpectedly on highly inflationary health systems. The rationalization and optimization of health services requires more care and medical analysis for one euro spent - goes through a better costeffectiveness ratio. The analysis of efficiency involves maximizing the quality of services, taking into account the existing economic constraints in order to improve health and satisfaction of the population. Such an intervention requires a possible integration of the population in the process of elaborating the quality standards of the medical services. On the other hand, it involves the analysis of health care and the impact on the reforms undertaken. For example, with regard to the management of institutions and the introduction of competitive relations, the aim is to use resources more efficiently and to improve the quality of healthcare for a lower cost. We are witnessing a multiplication of reforms on payment systems, regarding the reduction of waste of resources in the field of medical services and outpatient services. Health practices and technologies are subject to a more precise assessment to set priorities in the field. Policies are increasingly focusing on reorienting health systems towards measurable goals, both in terms of the quality of health care and the satisfaction of beneficiaries.

For each person, as well as for the whole community, health is one of the most important factors that ensure the development of life and activity. Health care is not only a health care problem, but also a problem with a deep social character, being an integral part of all socio-economic conditions of 
INTERNATIONAL JOURNAL OF ACADEMIC RESEARCH IN BUSINESS AND SOCIAL SCIENCES Vol. 10, No. 10, 2020, E-ISSN: 2222-6990 @ 2020 HRMARS

development. Medical policy is an integral part of social policy and significant financial resources are spent in many countries around the world. Health spending is on the rise due to factors such as:

- amplifying health care needs as an effect of population growth and structural change;

- accentuation of risk factors;

- the increase of the cost of medical services both as a result of the introduction in medical practice of new means of investigation, treatment, as well as an increase of the qualification and specialization of the medical staff.

The state budget and local budgets are the main resources available to the state and local authorities to finance public policy. Other state resources are social funds, set up through special contributions and with a precise destination. The level of public social spending reflects the degree of state involvement in the social protection of its citizens. However, the level of public social spending does not say anything about the way in which citizens are protected through social policies, so about the redistribution of welfare through the state. A second criterion for analyzing the profile of the welfare state is the nature of social programs and the share of different types of programs in total.

Health insurance is considered to be an essential objective of a health system whose main objectives are to achieve a high level of health and the equitable distribution of health care services. At the same time, a health system must correspond to the expectations of the population, which implies respect for the person (autonomy and confidentiality) and its orientation (prompt services and quality of facilities).

\section{Specificities of health systems in some European countries}

Health systems in EU Member States are funded by public or direct contributions. Each Member State has developed its own funding mechanisms. These funding systems are constantly undergoing change due to the fact that these countries are constantly evolving and changing, both in terms of the profile of diseases and the resources needed to cure and / or improve them.

\section{Austria}

The general law on social insurance enshrines the right to social protection and medical care. Based on the principle of compulsory public insurance, the Austrian social protection system covers $99 \%$ of the population (Bachner et al., 2018). The global health system is one of the best in the EU. Sickness insurance includes a very complete range of services, and the majority of the population (63.3\%) is very satisfied. Austria has seen a sharp rise in health spending, in line with the trend in all EU-based insurance schemes. Insurance is mandatory: $99 \%$ of the population is affiliated to one of the 24 health insurance companies. These are autonomous bodies. Their financing is essentially done through contributions (Theurl and Winner, 2007). About $40 \%$ of Austrians also have additional private insurance. The list of reimbursed drugs includes 2,700 products. Prices are set by ministerial decree. In the case of over-the-counter (OTC) products, pharmacists charge a maximum surcharge of $15 \%$ (Garel and Notarangelom, 2016).

\section{Belgium}

The Belgian health system is based on compulsory insurance, which covers the entire population (Gerkens and Merkur, 2010). The government sets the contribution quotas and defines the minimum level of coverage with medical benefits (Schokkaert and Van de Voorde, 2005). The national 
INTERNATIONAL JOURNAL OF ACADEMIC RESEARCH IN BUSINESS AND SOCIAL SCIENCES Vol. 10, No. 10, 2020, E-ISSN: 2222-6990 @ 2020 HRMARS

compulsory insurance system covers $88 \%$ of the population. Freelancers cover $12 \%$ of the population. The financing of the health system is based on health insurance contributions (36\%), taxation (38\%), direct payments (17\%). The remaining $9 \%$ is covered by additional insurance and indirect taxation (Garel and Notarangelom, 2016). Outpatient medical services are paid in part and directly by patients, which are reimbursed in the short term by insurance companies at an average of $75 \%$ and $25 \%$ of the costs are borne by patients. Medications are reimbursed based on a list. Prices are administered depending on the product category, the compensation varies up to $100 \%$. On average, $29 \%$ of the price is compensation.

\section{Denmark}

Since 1973, all Danish citizens have been enrolled in the national health service. It is entirely funded and planned by public authorities. Access to healthcare is universal and largely free. Funding is provided from taxes (Olejaz et al., 2012). The Danish health system is characterized by strong decentralization: the responsibility for organizing and managing the care offer is reserved for the 14 counties and the 275 municipalities (Garel and Notarangelom, 2016). For prescription drugs, cost sharing represents less than $8 \%$ of the product price. Dental care is free until the age of 18 . Then, the patients actually bear part of the costs. Hospitals are funded by municipalities, according to a system of payment per consultation and patient. Efforts to regulate health spending are focused on increasing cost-sharing, which is still low compared to the European Union average (Vrangbæk and Sorensen, 2013).

\section{Finland}

The Finnish health system is characterized by public planning and funding largely based on taxation (Vuorenkoski, Mladovsky and Mossialos, 2008). A 1993 survey found that $86.4 \%$ of Finns say they are very satisfied or satisfied with the health system. The responsibility for the health offer, the administration of medical services and the implementation of the health policy is delegated to the 455 municipalities, which collect a variable income tax, the average being $17 \%$. State subsidies and general tax financing represent 29\% (Garel and Notarangelom, 2016). The part not covered by the national social security regime amounts to $13 \%$ and is covered from private sources and from the direct participation of patients in costs (Hakkinen, 2010). The private insurance contribution is limited (2\%). General practitioners in health centers are paid employees according to a combined formula: $60 \%$ salary, payment per patient (20\%), payment based on documents, local allowances (5\%).

\section{France}

The model of the French healthcare system is distinguished by its hybrid nature, resulting from a complex combination of the private and public sectors in terms of supply and financing. In terms of life expectancy and mortality, France ranks among the first in the European Union (Chevreul et al., 2015). The financing of the health system is mainly based on contributions from employers and employees (Turquet, 2012). The French health insurance system covers $74.0 \%$ of total health expenditure. A share of $6.8 \%$ of expenditure is covered by the mutual society and $5.0 \%$ by private insurance. Taxation contributes less than $3.0 \%$, while patients' direct participation in costs amounts to more than $13.0 \%$ (Garel and Notarangelom, 2016). The percentage of patients' participation in costs is on average $20.0 \%$, but varies from zero (for medicines of strict necessity) to $65.0 \%$ for medicines for health maintenance. 
INTERNATIONAL JOURNAL OF ACADEMIC RESEARCH IN BUSINESS AND SOCIAL SCIENCES Vol. 10, No. 10, 2020, E-ISSN: 2222-6990 @ 2020 HRMARS

\section{Germany}

The German model is based on compulsory social security. The legal regime covers almost $88.0 \%$ of the population (Turquet, 2012). Affiliation is mandatory for workers whose incomes are below the ceiling. In $2015,75 \%$ of the population was affiliated to insurance under the compulsory system and $13 \%$ were optionally insured with one of the approximately 600 health insurance companies. For $10 \%$ of the population, health insurance is covered by employers, while the high-income population is insured with one of the 45 private insurance companies. Employees can choose their insurance company. Around $60.0 \%$ of the financing is covered by compulsory and optional state insurance, $21.0 \%$ by taxation, $7.0 \%$ by private insurance and $11.0 \%$ by direct participation in costs (Garel and Notarangelom, 2016). Contributions to insurance companies are paid in equal parts by both employees and employers (Busse and Blumel, 2014). The average value of the contribution amounts to about $13.5 \%$. The co-payment of hospital services has seen a gradual increase.

\section{Ireland}

The Irish health system is based on taxation, central public control and universal access to care (Thomas et al., 2014). Beneficiary satisfaction is close to the European average: $49.9 \%$ of Irish people say they are very satisfied or satisfied with the health system (EU-50.3\% average). At the regional level, the services are administered by eight regional health directorates, each serving between 200,000 and 1.2 million inhabitants. The system is financed in proportion of $78 \%$ from public funds. Participation in medical expenses covers about $13.5 \%$ of expenses (Garel and Notarangelom, 2016). Public funding is mainly based on taxes, as well as health insurance contributions which amount to $1.25 \%$ of gross income. In 1993, the Ministry of Health introduced an adjustment mechanism in the operation of the mix-cases treated in the process of allocating resources for large hospitals (Ryan, Thomas and Normand, 2009). Prescribed drugs are distributed free of charge on a separate list containing about 3,100 products. Prices are correlated with five other EU Member States.

\section{Italy}

The National Health Service (Servizio Sanitario Nazionale-SSN) was established in 1978, in order to ensure universal and free access to health care. The financing of the system is public, combining taxation with social health insurance. The implementation, planning, financing and control of the health system are the responsibility of 21 regions (Ferre et al. 2014). The financing of the health system is mostly public, $40.8 \%$ is insured from social insurance contributions and $37.5 \%$ from taxes (Garel and Notarangelom, 2016). A reform introduced in 1993 promotes additional insurance. Theoretically, employers pay $9.6 \%$ of gross income and employees $0.9 \%$, but actual contributions are variable. Hospitals use only the drugs listed on the recommended product lists. Patients pay $50 \%$ of the price of category B medicines in outpatient medicine or in hospital care. Category A medicines prescribed for serious or chronic diseases are free of charge (Reviglio, 2000).

\section{Netherlands}

The health system combines compulsory social insurance with private insurance. The first covered $62.0 \%$ of the population in 1993, and the second 31.0\% (Kroneman et al., 2016). Following the results of a survey conducted at European level, $72.8 \%$ of Dutch people say they are very satisfied or satisfied with the health system, compared to the European average of 50.3\% (Garel and Notarangelom, 2016). An important part of the population, around $37.0 \%$, mainly from the category of the richest 
INTERNATIONAL JOURNAL OF ACADEMIC RESEARCH IN BUSINESS AND SOCIAL SCIENCES Vol. 10, No. 10, 2020, E-ISSN: 2222-6990 @ 2020 HRMARS

and the self-employed, does not consider the compulsory regime advantageous and subscribes to a private insurance. The financing of the health system is dominated by social insurance, which took over $68.0 \%$ of health expenditures, while private insurance represents $13.7 \%$ of expenditures. Contributions to health insurance companies are paid according to salary income. One part is paid by the employer (5.15\% of gross income), and another by employees (1.15\%) (Van de Ven, van Vliet and Lamers, 2004).The actual participation of patients in the costs of medicines amounts to an average of $8.0 \%$ of their price.

\section{Spain}

The current Spanish health system was established by a general law in 1986. The Spanish National Health Service (Sistema Nacional de la Salud-SNS) which covers almost $98.5 \%$ of the population, of which $93 \%$ are affiliated under the general scheme, $1 \%$ receive allowances from the state and $4.5 \%$ (mainly civil servants) are affiliated to special schemes (Garcia-Armesto et al., 2010). About $17 \%$ of households have optional health insurance contracts. Insurance companies (mutual or private) play a minor role in the Spanish health system. About $80 \%$ of the funding comes from taxation, $18 \%$ comes from contributions paid according to income, both by employees and employers, and the difference of $2 \%$ comes from other forms of insurance (Prieto and Lago-Peñas, 2012). Drug prices are among the lowest in EU countries. A list of non-reimbursed medicines was established in 1993; it contained 800 products at the time. The co-payment for medicines amounts to an average of $32 \%$ of the price (Garel and Notarangelom, 2016).

\section{Sweden}

Health services are considered an important component of the Swedish social protection system. The population has access to a full range of care, which is covered by the national social insurance scheme, financed mainly by employer contributions. The health system is characterized by its strong decentralization: 23 general councils, as well as 3 large municipalities play an important role in planning, financing and providing health care on their territory (Thomson et al., 2012). Taxes collected by general councils cover most (around 65\%) of health expenditure. The rest comes from the social security system supplemented by state aid (18\%), from various public funds (10\%), private insurance (3\%) and to a small extent (4\%) from direct payments (Garel and Notarangelom, 2016). Prescribed drugs are on a list and are partially compensated by the national health insurance scheme. The compensation rates are modified based on a reference price. No cost sharing is required for medicines prescribed to hospital patients (Hultberg, Lonnroth and Allebeck, 2003).

\section{United Kingdom}

The National Health Service (NHS) has established universal access to health care since its inception (1948). The NHS is funded mainly by taxation (95\%) and other contributions (5\%) within a global budget set by the ministry and submitted to Parliament for approval (Fotaki and Boyd, 2005). There are devices based on insurance related to a small private sector that experienced a rapid leap during the 1990s. In 1996, 9\% of the population had an additional private health contract in order to cover specialized hospital services and avoid long delays in waiting for less urgent interventions. Private insurance covers only 3.5\% of expenditure, so funding is almost entirely focused on services provided within the NHS (Garel and Notarangelom, 2016). Moreover, the government has eliminated the tax cut in favor of private health insurance. There is a list of drugs that are compensated. Prices are set 
INTERNATIONAL JOURNAL OF ACADEMIC RESEARCH IN BUSINESS AND SOCIAL SCIENCES Vol. 10, No. 10, 2020, E-ISSN: 2222-6990 @ 2020 HRMARS

by producers, but the government exercises control over their profits (De Graeve and Van Ourti, 2003). Over-the-counter drugs are paid for in full by patients; With regard to the prescribed compensated medicines, the co-payment represents on average $24.0 \%$ of the price of the products.

As can be seen from the cited literature, the health systems in European countries differ significantly. The degree of decentralization of medical services and financing, the co-payment of services and drugs, the level and structure of financing, etc., are very heterogeneous. Our study analyzes the influence of these factors on the health of the population and on the accessibility of the correct medical services.

\section{Objectives, Hypotheses, Variables and Methodology}

Our study has the following two main objectives:

- Starting from the observations from the cited studies and using the regression analysis, we highlight the causal relationships between the financing of the health system, life expectancy and the quality and accessibility of medical services.

- Demonstrating the role of private health insurance as a factor influencing life expectancy and the quality and accessibility of medical services.

Based on the academic literature prior to previous studies and personal empirical observations, we formulate the following working hypotheses:

H1. The general level of financing of the health system positively influences the life expectancy and the accessibility to the medical services.

H2. The development of private health insurance leads to an increase in life expectancy and accessibility to medical services.

H3. The decentralization of medical services and their financing positively influences the life expectancy and accessibility of medical services.

\section{Variables}

LIFE_EXPECTANCY

Life Expectancy at birth indicates the number of years a newborn infant would live if prevailing patterns of mortality at the time of its birth were to stay the same throughout its life (for the distribution of the values in the sample see Appendix 1). Source: World Bank (2018).

\section{GHS_INDEX}

(possible values between 0 and 100) is a comprehensive assessment of global health security capabilities in 195 countries (for the distribution of the values in the sample see Appendix 1). The 140 GHS Index questions are organized across six categories: Prevention (Prevention of the emergence or release of pathogens), Detection and Reporting (Early detection and reporting for epidemics of potential international concern), Rapid Response (Rapid response to and mitigation of the spread of an epidemic, Health System (Sufficient and robust health system to treat the sick and protect health workers, Compliance with International Norms (Commitments to improving national capacity, financing plans to address gaps, and adhering to global norms) and Risk Environment (Overall risk environment and country vulnerability to biological threats). Source: GHS (2018). 
INTERNATIONAL JOURNAL OF ACADEMIC RESEARCH IN BUSINESS AND SOCIAL SCIENCES Vol. 10, No. 10, 2020, E-ISSN: 2222-6990 @ 2020 HRMARS

\section{HEALTH_EXPEDINTURE}

Level of current health expenditure $(\$)$. Estimates of current health expenditures include healthcare goods and services consumed during each year. This indicator does not include capital health expenditures such as buildings, machinery, IT and stocks of vaccines for emergency or outbreaks (for the distribution of the values in the sample see Appendix 2). Source: World Bank (2018).

\section{DENSITY}

Health Insurance Density (total premiums per inhabitant - domestic market) is calculated as the ratio of total insurance premiums (in Euros) to total population (for the distribution of the values in the sample see Appendix 2). Due to the large positive asymmetry and the nonlinear correlation with the explanatory variables, in regressions it will be used in its logarithmic form. Source: Insurance Europe (2018).

\section{DECENTRALIZATION}

The dummy variable that takes the value 1 if at least $10 \%$ of the financing of the health system comes from sources other than the public budget (budgets of local authorities, private financing, private health insurance, etc.) and the value 0 otherwise. Source: authors' calculations.

\section{Results and Discussion}

To test the hypotheses we chose a linear specification of the model and estimated the parameters using OLS regressions. The data from our study refer to 30 European countries. Their choice was not made by sampling, all European countries were included for which data are available for all variables included in the application. List of European countries in the sample: Austria (AT), Belgium (BE), Bulgaria (BG), Croatia (HR), Cyprus (CY), Czech Republic (CZ), Denmark (DK), Estonia (EE), Finland (FI), France (FR), Germany (DE), Greece (GR), Hungary (HU), Ireland (IE), Italy (IT), Latvia (LV), Luxemburg (LU), Malta (MT), Netherlands (NL), Norway (NO), Poland (PL), Portugal (PT), Romania (RO), Slovakia (SK), Slovenia (SI), Spain (ES), Sweden (SE), Switzerland (CH), Turkey (TR), United Kingdom (UK).

Table 1: Descriptive statistics of variables

\begin{tabular}{|l|c|c|c|c|}
\hline Variable & Min. & Max. & Mean & St. dev. \\
\hline LIFE_EXPECTANCY (years) & 74.8 & 83.8 & 80.3 & 2.69 \\
\hline GHS_INDEX & 45.6 & 75.6 & 59.7 & 8.11 \\
\hline HEALTH_EXPEDINTURE (\$) & 395 & 10228 & 3475 & 2529 \\
\hline DENSITY (\$) & 0.864 & 2719 & 235.8 & 521.8 \\
\hline DECENTRALIZATION (dummy) & 0 & 1 & 0.333 & 0.479 \\
\hline
\end{tabular}

Source: authors' calculations using data from Insurance World Bank (2018), Insurance Europe (2018) and GHS (2018)

In order to have an idea regarding the variables from the regressions we analyzed the descriptive statistics. In table 1 we present some significant parameters of the involved variables. We notice that the two endogenous variables have a high variability. There is a 9-year gap between the minimum and maximum value of LIFE_EXPECTANCY. Regarding GHS_INDEX, the dispersion of values among European countries is even greater. These variables involve several factors that can produce them: 
INTERNATIONAL JOURNAL OF ACADEMIC RESEARCH IN BUSINESS AND SOCIAL SCIENCES

Vol. 10, No. 10, 2020, E-ISSN: 2222-6990 @ 2020 HRMARS

the level and structure of financing, the complementarity due to private health insurance, different levels of decentralization of medical services.

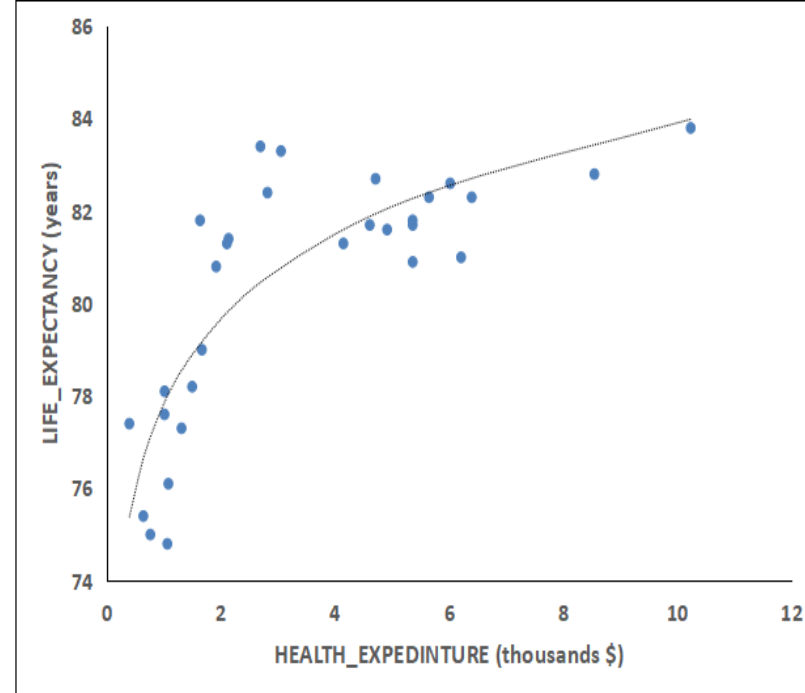

Fig. 1: Nonlinear correlation between LIFE_EXPECTANCY and HEALTH_EXPEDINTURE

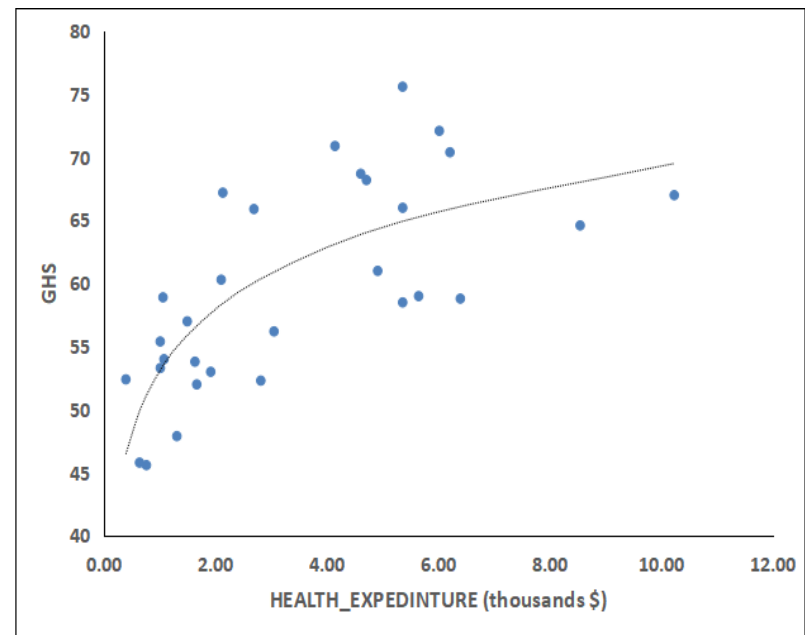

Fig. 3: Nonlinear correlation between GHS_INDEX and HEALTH_EXPEDINTURE

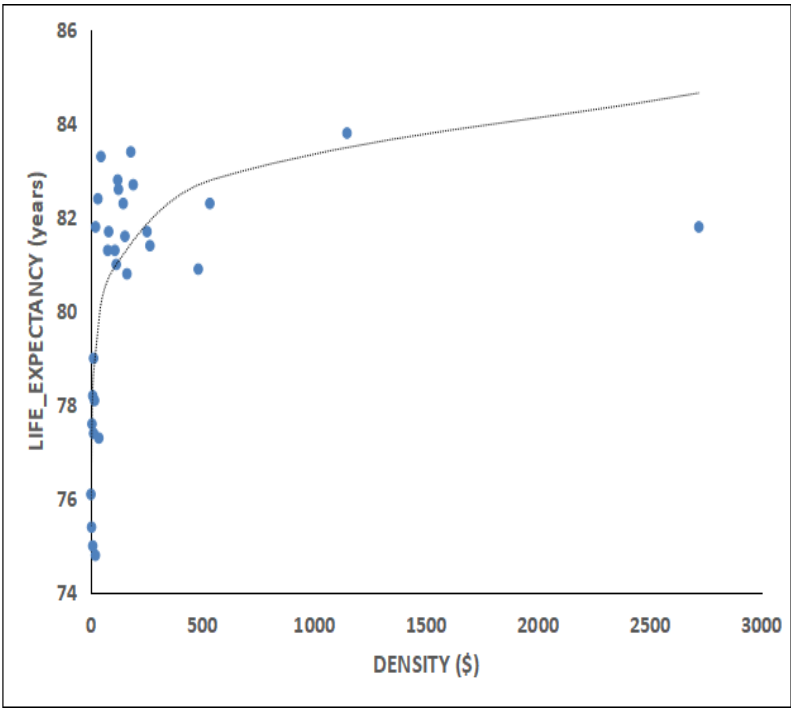

Fig. 2: Nonlinear correlation between LIFE_EXPECTANCY and DENSITY

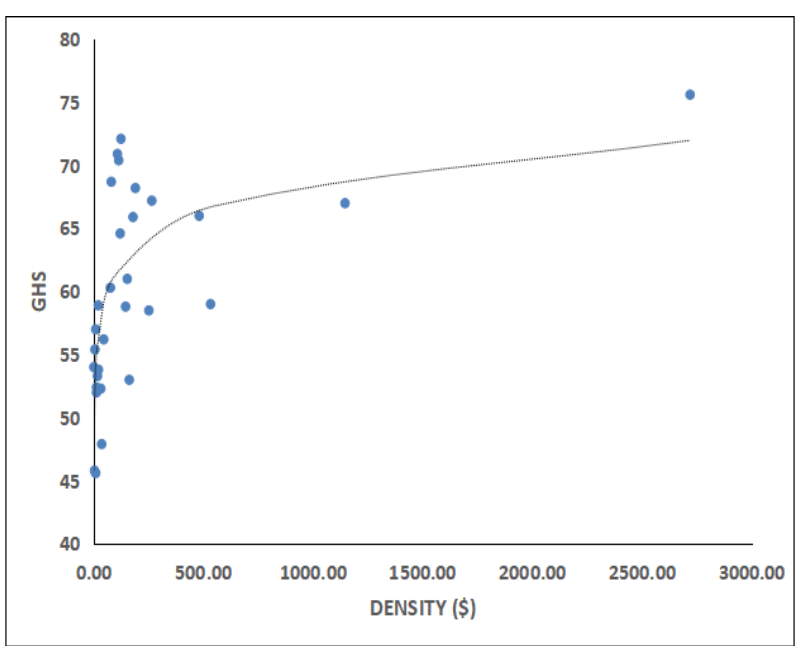

Fig. 4: Nonlinear correlation between GHS_INDEX and DENSITY

Figures 1, 2, 3 and 4 show that the correlation between any of the endogenous variables (LIFE_EXPECTANCY and GHS_INDEX) and any of the explanatory quantitative variables (HEALTH_EXPEDINTURE and HEALTH_EXPEDINTURE) is not linear, but rather logarithmic. As a result, the variables HEALTH_EXPEDINTURE and HEALTH_EXPEDINTURE will be used in regressions in their logarithmic form. 
INTERNATIONAL JOURNAL OF ACADEMIC RESEARCH IN BUSINESS AND SOCIAL SCIENCES Vol. 10, No. 10, 2020, E-ISSN: 2222-6990 @ 2020 HRMARS

Table 3: The coefficients of the OLS regressions on LIFE_EXPECTANCY and GHS (standard error and tstat)

\begin{tabular}{|l|r|r|r|r|}
\hline & \multicolumn{2}{|c|}{$\begin{array}{r}\text { Dependent variable: } \\
\text { LIFE_EXPECTANCY }\end{array}$} & \multicolumn{2}{r|}{$\begin{array}{r}\text { Dependent variable: } \\
\text { GHS_INDEX }\end{array}$} \\
\cline { 2 - 5 } & OLS 1 & OLS 2 & OLS 3 & OLS 4 \\
\hline Ln HEALTH_EXPEDINTURE & $* * * 2.234$ & & $* * * 5.517$ & \\
& $(4.67)$ & & $(3.39)$ & \\
\hline Ln DENSITY & 0.295 & $* * * 1.146$ & 1.136 & $* * * 3.245$ \\
& $(1.30)$ & $(6.10)$ & $(1.47)$ & $(5.35)$ \\
\hline DECENTRALIZATION & $* * * 1.536$ & & $* * * 6.485$ & \\
& $(2.99)$ & & $(3.72)$ & \\
\hline Constant & $* * * 61.05$ & $* * * 75.58$ & 9.551 & $* * * 46.31$ \\
& $(19.6)$ & $(9.68)$ & $(0.91)$ & $(17.01)$ \\
\hline & $\mathrm{R}^{2}=0.789$ & $\mathrm{R}^{2}=0.571$ & $\mathrm{R}^{2}=0.731$ & $\mathrm{R}^{2}=0.505$ \\
\hline
\end{tabular}

$* * *, * *, *$ : significant at $1 \%, 5 \%$ and $10 \%$ level

Source: own calculations using STATA 14 software.

The results of the regressions are very clear for the variable Ln HEALTH_EXPEDINTURE, it being very statistically significant (Table 2), even in the presence of the other explanatory variables and even if it is correlated with them. There is a positive influence both on the lifespan (LIFE_EXPECTANCY) and on the accessibility to a quality sanitary system (GHS_INDEX). As a result, the $\mathrm{H} 1$ hypothesis is fully accepted. However, some more detailed analysis may be needed. Expenditures on health services were analyzed only as a total volume. Due to the lack of data, we could not evaluate the effect of the structure of these expenditures on the health of the population. Even the effect of the ratio of doctors' salaries versus the financing of medical equipment and medicines could provide important information. Similarly, the ratio of amounts spent on treatment versus prevention could be relevant.

The role of the level of private health insurance is not as clear. The variable DENSITY is statistically significant if it is alone in regressions, but statistically insignificant in the presence of the other explanatory variables. The result can be explained by the strong correlation with HEALTH_EXPEDINTURE (Pearson coefficient $=0.794$, see table 2 ), even higher than the correlation with endogenous variables. Consequently, we accept the $\mathrm{H} 2$ hypothesis with reservations. The role of private health insurance should be clarified more clearly. In addition, in different European countries, the legislation on these insurances is different. In some cases the contribution is mandatory, and in others it is optional. It is interesting to study the relationship between public funding of media services and private health insurance. This could be a relationship of substitutability or complementarity.

The decentralization of medical services clearly has a positive and significant role (Table 2), both on the lifespan (LIFE_EXPECTANCY) and on the accessibility to a quality health system (GHS_INDEX). As a result, we accept hypothesis H3. However, it would be interesting to study the structure of decentralization. This concept refers to the decentralization of hospital financing, doctors' salaries, drug subsidies, prevention programs, etc. Each component may have a different role on 
INTERNATIONAL JOURNAL OF ACADEMIC RESEARCH IN BUSINESS AND SOCIAL SCIENCES Vol. 10, No. 10, 2020, E-ISSN: 2222-6990 @ 2020 HRMARS

LIFE_EXPECTANCY and GHS_INDEX. However, this issue is very complex and would require a separate theoretical and empirical study.

Table 2: The matrix of the correlation (Pearson) coefficients

\begin{tabular}{|l|c|c|c|c|c|}
\hline & $(1)$ & $(2)$ & $(3)$ & $(4)$ & (5) \\
\hline LIFE_EXPECTANCY (1) & 1.000 & & & & \\
\hline GHS_INDEX (2) & 0.633 & 1.000 & & & \\
\hline Ln HEALTH_EXPEDINTURE (3) & 0.832 & 0.739 & 1.000 & & \\
\hline Ln DENSITY (4) & 0.755 & 0.711 & 0.794 & 1.000 & \\
\hline DECENTRALIZATION (5) & 0.212 & 0.334 & -0.091 & 0.104 & 1.000 \\
\hline
\end{tabular}

\section{Conclusions}

Our study is not intended to exhaustively explain the factors that determine health, longevity and accessibility to health services in a country. However, we managed to highlight the positive role of public funding, private health insurance and the decentralization of the health system. There are also some limitations of the study, mainly due to the lack of more detailed data, especially those related to the funding structure. The implications of the results are important for both the population and policymakers. Institutional managers of health care systems may make some decisions consistent with the influence of regression models. Taking into account the identified nonlinear functional relationships, points of maximum or inflection for the efficiency of health care can be determined at the level of each country. The construction of health indicators provided in relation to the amounts invested and their consistent follow-up can bring important benefits in the design of the health system.

Our study contributes to the current state of scientific research primarily through the empirical results obtained. We highlighted the correlations between the financing of the medical system, the development of private health insurance, life expectancy, the quality of the medical system and the decentralization of the organization of health services. Moreover, we identified the nonlinear (logarithmic) functional form between certain variables. The functions that shape the causality between concepts can be used for descriptive analysis or predictions. For example, it can be analyzed in each country in the sample whether the medical system and human health are overperforming or underperforming in relation to the values of influencing factors such as health financing and private life insurance in that country.

\section{Funding}

This work was supported by a grant of the Romanian Ministry of Education and Research, CNCS UEFISCDI, project number PN-III-P1-1.1-TE-2019-0554, within PNCDI III. 
INTERNATIONAL JOURNAL OF ACADEMIC RESEARCH IN BUSINESS AND SOCIAL SCIENCES Vol. 10, No. 10, 2020, E-ISSN: 2222-6990 @ 2020 HRMARS

\section{Appendix}

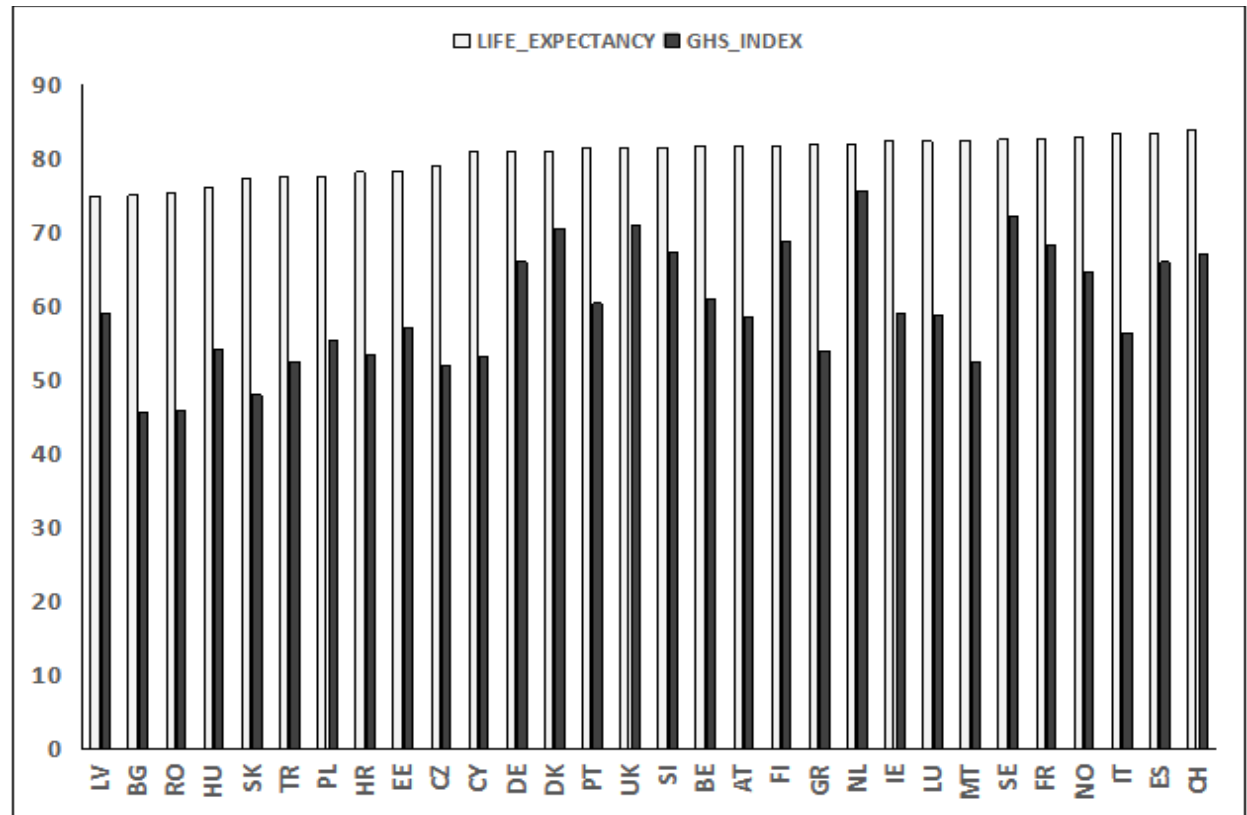

Appendix 1: Distribution of variable values LIFE_EXPECTANCY and GHS_INDEX in the 30 European countries in the sample

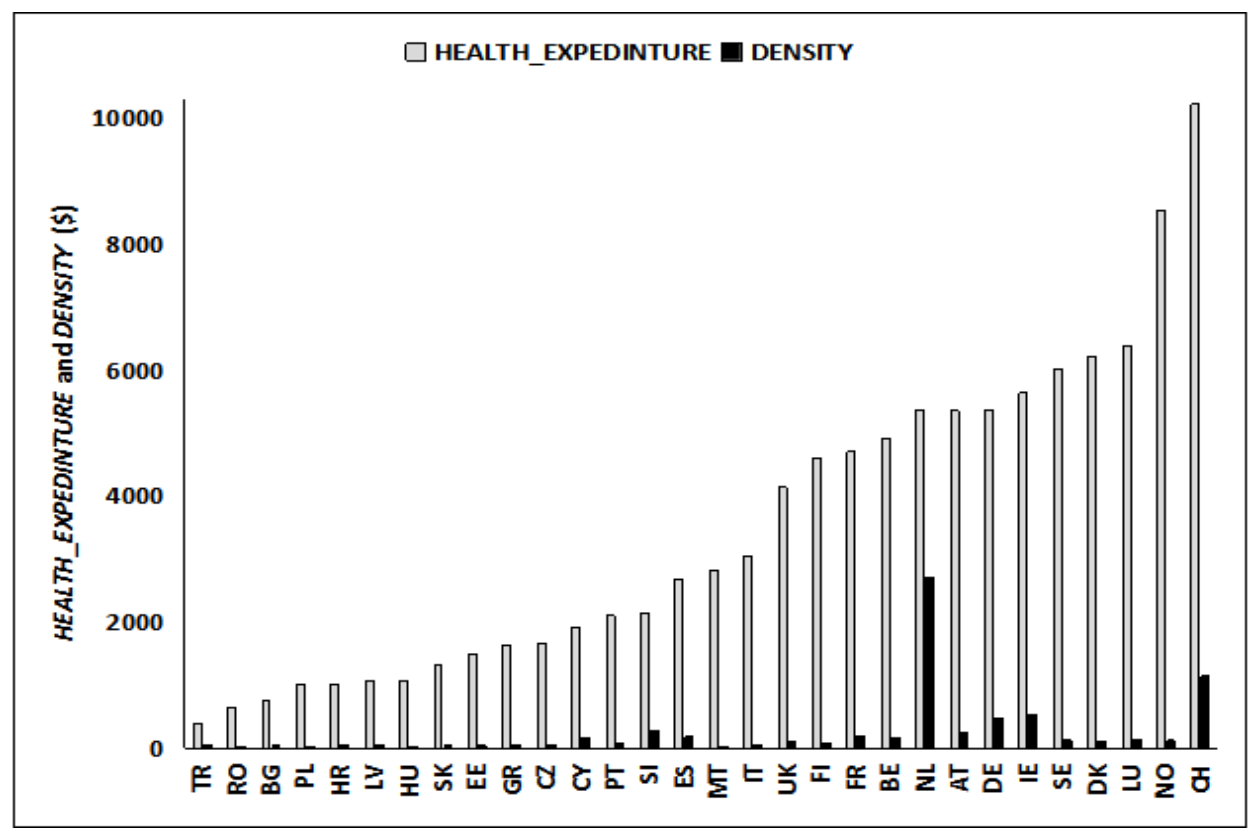

Appendix 2: Distribution of variables values HEALTH_EXPEDINTURE and DENSITY in the 30 European countries in the sample 
INTERNATIONAL JOURNAL OF ACADEMIC RESEARCH IN BUSINESS AND SOCIAL SCIENCES

Vol. 10, No. 10, 2020, E-ISSN: 2222-6990 @ 2020 HRMARS

\section{References}

Bachner, F., Bobek, J., Habimana, K., Ladurner, J., Leuschutz, L., Ostermann, H., \& Winkelmann, J. (2018). Austria: Health system review.

Busse, R., \& Blumel, M. (2014). Germany. Health system review.

Chevreul, K., Brigham, B., Durand-Zaleski, I., \& Hernandez-Quevedo, C. (2015). France: Health system review. Health systems in transition, (17/3).

De Graeve, D., \& Van Ourti, T. (2003). The distributional impact of health financing in Europe: A review. World Economy, 26(10), 1459-1479.

Ferre, F., de Belvis, A. G., Valerio, L., Longhi, S., Lazzari, A., Fattore, G., Ricciardi, W., \& Maresso, A. (2014). Italy: health system review.

Fotaki, M., \& Boyd, A. (2005). From plan to market: a comparison of health and old age care policies in the UK and Sweden. Public Money \& Management, 25(4), 237-243.

Garel, P., Notarangelom, I. (2016). Hospitals in Europe: Healthcare data. hospitalhealthcare.com

Garcia-Armesto, S., Abadia-Taira, M., Duran, A., Hernandez-Quevedo, C., \& Bernal-Delgado, E. (2010). Spain: Health system review.

Gerkens, S., \& Merkur, S. (2010). Belgium: Health system review. Health systems in transition, 12(5), 1-266.

Hakkinen, A., Rinne, M., Vasankari, T., Santtila, M., Hakkinen, K., \& Kyrolainen, H. (2010). Association of physical fitness with health-related quality of life in Finnish young men. Health and quality of life outcomes, 8(1), 15-31

Hultberg, E. L., Lonnroth, K., \& Allebeck, P. (2003). Co-financing as a means to improve collaboration between primary health care, social insurance and social service in Sweden. A qualitative study of collaboration experiences among rehabilitation partners. Health Policy, 64(2), 143152.

Kroneman, M., Boerma, W., Van den Berg, M., Groenewegen, P., De Jong, J., \& van Ginneken, E. (2016). Netherlands: health system review.

Pintea, A. (2020). Study on ways for sustainable financing of health systems. Doctoral thesis, BabesBolyai University of Cluj Napoca.

Prieto, D. C., \& Lago-Peñas, S. (2012). Decomposing the determinants of health care expenditure: the case of Spain. The European Journal of Health Economics, 13(1), 19-27.

Olejaz, M., Nielsen, A., Rudkjobing, A., Birk, H., Krasnik, A., \& Hernandez-Quevedo, C. (2012). Denmark: Health system review.

Reviglio, M. F. (2000). Health care and its financing in Italy: issues and reform options (No. 0-166). International Monetary Fund.

Ryan, P., Thomas, S., \& Normand, C. (2009). Translating Dutch: challenges and opportunities in reforming health financing in Ireland. Irish journal of medical science, 178(3), 245-248.

Schokkaert, E., \& Van de Voorde, C. (2005). Health care reform in Belgium. Health economics, 14(S1), S25-S39.

Theurl, E., \& Winner, H. (2007). The impact of hospital financing on the length of stay: evidence from Austria. Health policy, 82(3), 375-389.

Thomas, S., Keegan, C., Barry, S., Layte, R., Jowett, M., \& Normand, C. (2013). A framework for assessing health system resilience in an economic crisis: Ireland as a test case. BMC Health Services Research, 13(1), 450-464 
INTERNATIONAL JOURNAL OF ACADEMIC RESEARCH IN BUSINESS AND SOCIAL SCIENCES

Vol. 10, No. 10, 2020, E-ISSN: 2222-6990 @ 2020 HRMARS

Turquet, P. (2012). Health insurance system financing reforms in the Netherlands, Germany and France: Repercussions for coverage and redistribution?. International Social Security Review, 65(1), 29-51.

Van de Ven, W. P., Van Vliet, R. C., \& Lamers, L. M. (2004). Health-adjusted premium subsidies in the Netherlands. Health Affairs, 23(3), 45-55.

Vrangbæk, K., \& Sorensen, L. M. (2013). Does municipal co-financing reduce hospitalisation rates in Denmark?. Scandinavian journal of public health, 41(6), 616-622.

Vuorenkoski, L., Mladovsky, P., \& Mossialos, E. (2008). Finland: Health system review. 